\title{
Estimating population parameters of longsnout seahorses, Hippocampus reidi (Teleostei: Syngnathidae) through mark-recapture
}

\author{
Alexandre C. Siqueira ${ }^{1,2}$, Juan P. Quimbayo ${ }^{1,3}$, Mauricio Cantor ${ }^{4}$, Rosana B. Silveira ${ }^{5}$ \\ and Fábio G. Daura-Jorge ${ }^{4}$
}

Estimating population parameters is essential for understanding the ecology of species, which ultimately helps to assess their conservation status. The seahorse Hippocampus reidi is directly exposed to anthropogenic threats along the Brazilian coast, but the species still figures as Data Deficient (DD) at IUCN's Red List. To provide better information on the ecology of this species, we studied how population parameters vary over time in a natural subtropical environment. By combing mark-recapture models for open and closed populations, we estimated abundance, survival rate, emigration probability, and capture probability. We marked 111 individuals, which showed a 1:1 sex ratio, and an average size of $10.5 \mathrm{~cm}$. The population showed high survival rate, low temporary emigration probability and variable capture probability and abundance. Our models considering relevant biological criteria illuminate the relatively poorly known population ecology and life history of seahorses. It is our hope that this study inspires the use of mark-recapture methods in other populations of $H$. reidi in a collective effort to properly assess their conservation status.

Keywords: Capture Probability, Emigration Probability, Population Ecology, Robust Design, Survival Rate.

Parâmetros populacionais são essenciais para compreender a ecologia das espécies, além de auxiliar a avalição do seu status de conservação. Dentre as espécies de cavalo-marinho que ocorrem no Brasil, Hippocampus reidi é a mais abundante, o que expõe suas populações a frequentes ameaças antropogênicas. Entretanto, esta espécie ainda consta como Deficiente em Dados (DD) na lista vermelha da IUCN. Considerando esta falta de informações sobre populações de H. reidi, utilizamos métodos de marcação e recaptura para avaliar como parâmetros de uma população de ambiente subtropical variam ao longo do tempo. Baseado em históricos de captura individuais, combinamos modelos de populações abertas e fechadas para estimar abundância, taxa de sobrevivência, probabilidade de emigração e probabilidade de captura. Ao todo, marcamos 111 indivíduos, em proporção sexual de 1:1, e tamanho médio de 10,5 cm. Esta população relativamente pequena apresentou alta taxa de sobrevivência, baixa probabilidade de emigração temporária e probabilidade de captura e abundância variáveis. A partir dos nossos modelos que consideraram critérios biológicos relevantes, fornecemos estimativas de parâmetros chave que auxiliarão a compreensão da ecologia e da história de vida de cavalos-marinhos. Nossa expectativa é que este método passe a ser amplamente utilizado em outras populações, em um esforço coletivo para avaliar o estado de conservação desta espécie.

Palavras-chave: Desenho Robusto, Ecologia de Populações, Probabilidade de Captura, Probabilidade de Emigração, Taxa de Sobrevivência.

\section{Introduction}

Comprehending how populations interact with ecological and evolutionary factors is a primary motivation in population ecology. An essential step towards this goal is the quantification of parameters of wild populations, which also provides the baseline information to assess the conservation status of a species (Lebreton et al., 1992; Dulvy et al., 2004). Markrecapture techniques provide outstanding tools for estimating these parameters across taxa (e.g. Bjorndal et al., 2003; Hammond, Anthony, 2006; Rotheray et al., 2014). By tracking the capture history of marked individuals in a local population, one can accurately estimate abundance, survival, movements — to name but a few parameters (e.g. White, Burnham, 1999).

${ }^{1}$ Laboratório de Biogeografia e Macroecologia Marinha, Departamento de Ecologia e Zoologia, Universidade Federal de Santa Catarina,
Edifício Fritz Müller, $2^{\circ}$ andar, 205B, 88040-970 Florianópolis, SC, Brazil. (ACS) alesixbio@gmail.com (corresponding author)
${ }^{2}$ College of Science and Engineering \& ARC Centre of Excellence for Coral Reef Studies, James Cook University, 4811, Townsville, QLD,
Australia (current address).
${ }^{3}$ Grupo de Investigación en Ecología de Arrecifes Coralinos. Departamento de Biología, Universidad del Valle, Apartado Aéreo, 25360,
Cali, Colombia. (JPQ) quimbayo.j.p@gmail.com
${ }^{4}$ Laboratório de Mamíferos Aquáticos, Departamento de Ecologia e Zoologia, Universidade Federal de Santa Catarina, Edifício Fritz
Müller, ${ }^{\circ}$ andar, 88040-970 Florianópolis, SC, Brazil. (MC) m.cantor@ymail.com, (FGDJ) daurajorge@gmail.com
${ }^{5}$ Laboratório de Aquicultura Marinha, Projeto Hippocampus, Rua da Esperança, 55590-000 Ipojuca, PE, Brazil. (RSRBS) labaquac@yahoo.com 
The number of individuals in a given population (i.e., abundance) essentially reflects the balance between addition through birth and immigration, and losses through deaths and emigration (Williams et al., 2002). Traditionally, estimates of abundance were based on mark-recapture models of closed populations, which assume negligible addition, loss, and movement of individuals between subpopulations. However, this assumption does not hold true in many cases, especially in studies spanning over large spatiotemporal scales (Kendall et al., 1997). Too often, individuals are part of meta-populations in which emigration and immigration exert a strong influence in the balance of individuals over time (Hanski, 1998). To account for this influence, models of closed and open populations were combined (Pollock, 1982; Kendall et al., 1997), allowing precise estimates of abundance, temporary emigration, and survival probabilities in mark-recapture studies. This inclusive model, known as Pollock's Robust Design (Kendall et al., 1997), has been successfully applied to a wide range of species in different habitats (e.g. Frick et al., 2010; Cantor et al., 2012; Wayne et al., 2016), providing essential information about population ecology. Besides being important for understanding basic life history parameters, this framework has been proven to be valuable for assessing population trends of threatened species, required to guide conservation initiatives.

Pipefishes, pipehorses, seahorses and seadragons belong to the Syngnathidae family, which comprises around 300 species of characteristic long-snouted fish with fused jaws and male brooding, inhabiting temperate and tropical coastal waters (Hamilton et al., 2017). The mark-recapture approach has been successfully employed to study life history traits, behavior and movement patterns of some of these species (e.g. Connolly et al., 2002; Bell et al., 2003; Silveira, 2005; Curtis, Vincent, 2006; Caldwell et al., 2011). Despite such effort, key population parameters remain poorly known for most Syngnathids, hindering a broader understanding of how dynamic their natural populations can be over time. To date, few studies have quantified the parameters that allow evaluation of population trends, such as abundance, survival, immigration and emigration (but see Sanchez-Camara et al., 2006). This gap is critical given that natural populations of some of these species seem to be declining (Martin-Smith, Vincent, 2005).

The major causes of decline in populations of Syngnathidae species are the intensive exploitation for traditional medicine and the aquarium industry, and the disturbance of natural habitats by a myriad of human coastal activities (Lourie et al., 2004). Amongst the species that are particularly vulnerable to anthropogenic threats are the seahorses of the genus Hippocampus Rafinesque, 1810, because they are coastal, have small home ranges and tend to be highly associated with the substrate (Foster, Vincent, 2004). This alarming situation led to the inclusion of 38 Hippocampus species in IUCN's Red List in 1996 (IUCN, 2016), as well as the addition of the genus in Appendix II of the Convention on International Trade in Endangered Species of Wild Fauna and Flora in 2004 (CITES, 2016).
Eight species of this genus occur in the Atlantic Ocean. One of the most widespread is the longsnout seahorse Hippocampus reidi Ginsburg, 1933, which ranges from the Caribbean to the southern coast of Brazil (Teske et al., 2007). This species is abundant in reef and estuarine environments along the coast (Silveira, 2011), but their population dynamics remain mostly unknown (but see Silveira, 2005; Mai, Velasco, 2011; Silveira et al., 2016). The study of natural populations is limited to the tropical northeastern Brazilian coast (Silveira, 2005; Mai, Rosa, 2009; Mai, Velasco, 2011), while in the south subtropical coast, studies are much rarer and restricted to artificial environments (e.g. Freitas, Velastin, 2010). There has been a single effort to characterize natural populations of $H$. reidi along the Brazilian coast (Rosa et al., 2007). This lack of basic population parameters estimation is the primary factor preventing a proper assessment of the conservation status of the species, which still figures as Data Deficient (DD) status on the IUCN's Red List.

Aiming to better understand the basic ecology and life history of this poorly known species, we assessed key population parameters of longsnout seahorses in situ, in a natural subtropical environment. By combining markrecapture methods for open and closed populations, we estimate survival probabilities, abundance, movements, sex ratio and size of individuals. Our study provides important empirical ecological information that could be used as a baseline for larger-scale population assessments aiming to clarify the definition of the conservation status of this species.

\section{Material and Methods}

Study site. We carried out a mark-recapture experiment in the rocky shores of Sepultura beach $\left(27^{\circ} 08^{\prime} \mathrm{S} 48^{\circ} 28^{\prime} \mathrm{W}\right)$, southern Brazil (Fig. 1). The beach is relatively protected from waves, providing conditions for shallow water organisms including many fish and invertebrate species. The local benthic community is predominantly composed of the sessile Sargassum algae, which seahorses are commonly associated with (Coston-Clements et al., 1991).

Data sampling. For a full year (April 2011 to April 2012), we searched for seahorses during free diving (snorkeling) surveys. Sargassum banks occurred at the maximum depth of three meters, making SCUBA diving unnecessary. Two researchers actively searching for seahorses during 1 hour (totaling 2 hours per occasion) throughout the entire study area $\left(1,800 \mathrm{~m}^{2}\right)$ defined a capture occasion. Each animal we located was placed into a plastic pot with water and substrate to minimize stress during measurements. On the beach, the following individual biological data were recorded: sex, color, and length (linear measurement from the top of the head to the tail, Lourie et al., 2004). The presence (male) or absence of the pouch (female) in specimens longer than 10.1 $\mathrm{cm}$ determined sex. Individuals smaller than $10.0 \mathrm{~cm}$ were considered juveniles (Silveira, 2005). 


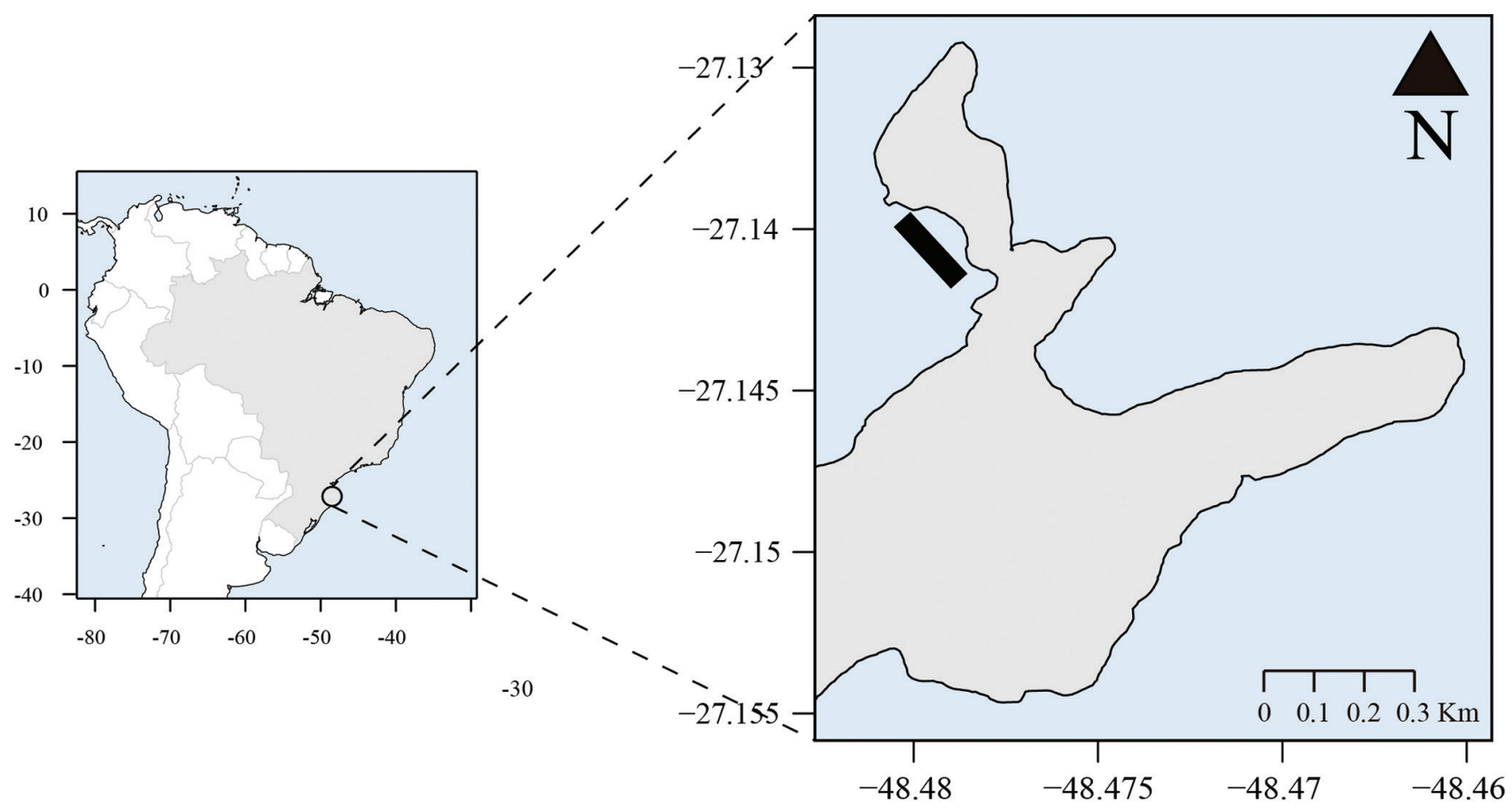

Fig. 1. Sampling area location (black stripe) at Sepultura beach on the southern coast of Brazil.

We marked all individuals in the first rings of the trunk with numbered collars. We placed the collars so as not to harm the animal, keeping a clearance to avoid injury. This method is commonly used in mark-recapture studies with Syngnathidae, with little influence on its natural behavior (Caldwell et al., 2011). After marking, individuals were released in the same place of capture. We assessed the efficiency of our sampling effort with a discovery curve built with sample-based rarefaction methods (Gotelli, Colwell, 2001) in R environment (R Development Core Team 2016). An asymptotic discovery curve was diagnostic of sufficient sampling effort.

Mark-recapture modelling procedures. We organized the mark-recapture data over a six-month period between November 2011 and April 2012, totaling 24 sampling days. The previous six months (April-November 2011) consisted of a pilot sampling effort, with only one capture occasion per month. We analyzed the binary matrix of capture history of all marked individual in the MARK program (version number 8.1; White, Burnham, 1999).

Our sampling effort was designed to model population parameters using the Pollock's Robust Design (Pollock, 1982; Kendall et al., 1997). This framework considers primary and secondary sampling occasions to combine open and closed population models. We then divided our sampling occasions among the six months and 24 days as follows: each month was considered a primary period in which we had four days of sampling, regarded as the secondary periods. We concentrated these four sampling days in the first 15 days of the month and spaced them by three days. This approach allowed us to consider the population within secondary occasions as closed, that is, the three-day intervals between these sampling occasions were short enough so we could assume no changes in the population, allowing accurate abundance estimates $(\mathrm{N})$.

Between the primary occasions, we considered the population as open, assuming that individuals could enter or leave the population between months. This approach enabled the estimation of apparent survival probabilities $(\phi)$ and capture and recapture probabilities ( $p$ and $c$ ). The temporary emigration estimates $\left(\gamma^{\prime}\right.$ and $\left.\gamma^{\prime \prime}\right)$ were made possible by analyzing the set of primary and secondary occasions following Kendall, Nichols (1995). We used a conditional parameterization of the Robust-Design models, also known as "Huggins closed model" (Huggins, 1989). The Huggins robust-design closed model compute abundance as a derived parameter. In other words, the statistical model does not contain abundances as parameters. Huggins parameterization allows including individual covariates and is more stable in recognizing parameters.

We built 10 candidate models to estimate the following parameters: capture probability within $\left(p^{\prime}\right)$ and between $(p)$ secondary periods, survival probabilities $(\phi)$, temporary emigration probabilities ( $\gamma$ ") between primary periods (i.e., the probability that an individual emigrant remained outside the study area $\left(\gamma^{\prime}\right)$ during subsequent primary periods; Kendall, Nichols, 1995; Kendall et al., 1997) and abundance $(\mathrm{N})$ of marked individuals within each pair of secondary periods. We also tested different movement patterns, considering completely random $\left(\gamma^{\prime \prime}=\gamma^{\prime}\right)$ or Markovian emigration models ( $\left.\gamma^{\prime \prime} \gamma^{\prime}\right)$, or no emigration models $\left(\gamma^{\prime \prime}=\gamma^{\prime}=0\right)$ (see Kendall et al., 1997). Candidate models were built assuming, or not, the time-dependence 
(t) or group (g) (sex - female, male or juveniles) effects in the parameters of interest $\left(p^{\prime}, p, \phi, \gamma\right)$. Since our method for capturing and marking individuals could be considered as invasive (Correia et al., 2014), we also tried the model with behavioral responses $(p \neq c)$.

We used the quasi-Akaike's Information Criterion adjusted for small sample size and extra binomial variation (QAICc; Burnham, Anderson et al., 1992) to select the most parsimonious model (i.e., the model that best explains the variation of data with the smaller number of parameters). To incorporate the uncertainty of the model selection process into our parameter estimates, we used the model averaging method. Differences in AICc values were used to compute the model weights, which were then used to determine the weighted average of the parameters based on the relative importance of the models using MARK.

Model assumptions. Multiple samples mark-recapture estimates of population parameters depend on the following assumptions (Otis et al., 1978; Seber, 1982): (i) animals do not lose their marks during the experiment; (ii) all marks are correctly recorded in each recapture event; (iii) each animal has an equal and constant capture probability; (iv) each animal has an equal and constant survival probability. For closed models, we also assume (v) the population does not change in composition during the sampling periods. Violation of these assumptions causes sampling heterogeneity, resulting in extra-binomial variation, or overdispersion (Williams et al., 2002). We tried to reduce variations by discarding the data on poorly marked (i.e., tags with unidentifiable scraped numbers) seahorses from our sampling subset, only including the identifiable collars in our capture-recapture dataset (limiting violations of assumptions $i$ and $i$ ). Since there are no appropriate methods for testing the goodnessof-fit (GOF) in RF models (White, Burnham, 1999), we measured overdispersion of the data using a general CJS model, based on primary periods collapsed from the Robust Design matrix, estimating the variance inflation factor $(\hat{c})$ by Bootstrapping with 1000 iterations (White, Burnham, 1999). Where $\hat{c}$ was $>1$, the estimated value was used to adjust the models.

Analysis of other population aspects. To estimate sex ratio, we have only used the data on sexually mature individuals. This is because juveniles were rarely sighted due to their small sizes and had no secondary sexual characters that were visually identifiable. We used a chi-square test to verify if there were differences between the number of males and females.

\section{Results}

Population characterization. We captured and marked 111 individuals of $H$. reidi, out of which 49 were males, 51 females, and 11 juveniles. The population showed sex ratio of $1: 1$, with no significant difference between sexes $\left(\mathrm{X}^{2}=0.02, \mathrm{df}=1, p=0.88\right)$. Body size ranged from 6.0 to 15.5 $\mathrm{cm}$ (mean $\pm \mathrm{SD}$; males $=10.30 \pm 1.85 \mathrm{~cm}$; females $=10.70 \pm$ $1.74 \mathrm{~cm}$ ). The smallest male with forming pouch was 6.6 $\mathrm{cm}$ length. Juveniles and reproductively active animals with pregnant pouch were found throughout the entire duration of the studied year, and two couples were spotted mating during our mark-recapture sampling occasions. All animals were found associated with Sargassum macroalgae.

Robust Design results. There were 336 recapture events throughout the mark-recapture sampling occasions. The discovery curve (Fig. 2) tended to be asymptotic, with narrower $95 \%$ confidence intervals towards the end of the study, indicating that sampling effort was sufficient to mark most of the individuals in the population.

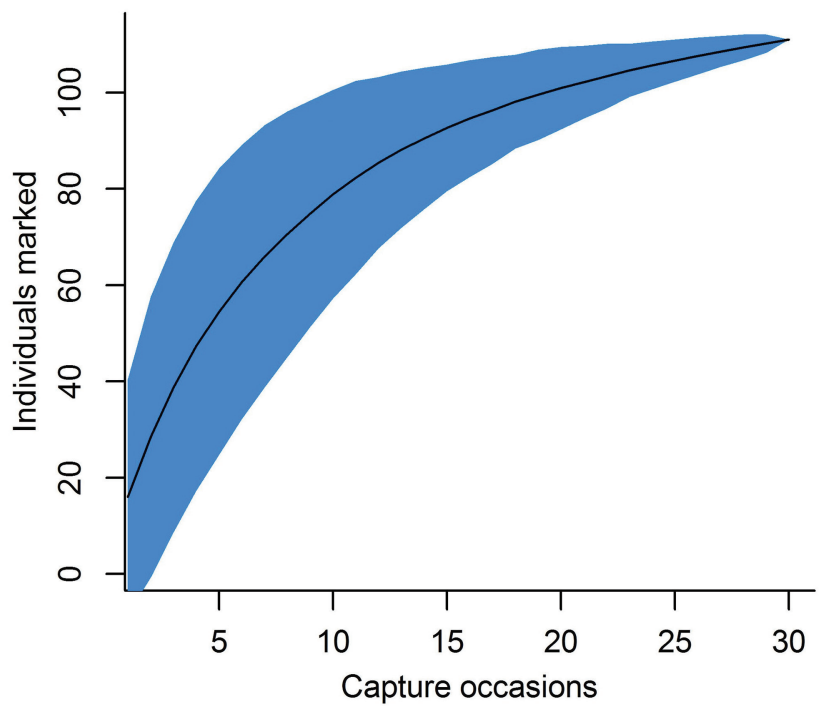

Fig. 2. Sample-based discovery curve of marked Hippocampus reidi at Sepultura beach. The black curve represents the rarefaction estimate and blue area the $95 \%$ confidence intervals.

Tab. 1. provides all candidate models ranked (adjusted by a c-hat of 2.41) according to their lowest quasi-Akaike Information Criterion (QAICc). The most parsimonious model considered random temporary emigration with no time-dependence $\left(\gamma^{\prime}()=.\gamma^{\prime \prime}().\right)$; constant apparent survival probabilities with no time-dependence and group effect $(\phi()$.$) ; and capture probability equal to recapture probability$ and time-dependent over primary and secondary periods $(p(t s)=c(t s))$. With this model, the survival rate was estimated to be relatively high $(\phi=0.83 \pm 0.05 \mathrm{SE}-95 \% \mathrm{CI}=0.71-$ 0.91 ) and emigration probability to be low throughout the study $(\gamma "=0.19 \pm 0.08 \mathrm{SE}-95 \% \mathrm{CI}=0.07-0.42)$. Capture and recapture probabilities were variable, and ranged between $0.08 \pm 0.07 \mathrm{SE}$ and $0.76 \pm 0.09$ SE. Likewise, abundance $(\mathrm{N})$ varied throughout the study and ranged from $12 \pm 2.23 \mathrm{SE}$ to $24 \pm 0.8 \mathrm{SE}$ males and $7 \pm 1.7 \mathrm{SE}$ to $31 \pm 0.8$ SE females in primary capture occasions (Fig. 3). Based on these abundance estimates, we estimated densities ranging from 0.3 to 1.7 individuals $/ 100 \mathrm{~m}^{2}$ at Sepultura beach. 
Tab. 1. Robust Design candidate models to estimate survival probability $(\phi)$, capture probability $(p)$ and temporary emigration probability $(\gamma)$ for Hippocampus reidi. Models are ranked by the lowest quasi-Akaike's Information Criterion with a $2^{\text {nd }}$-order correction for small sample sizes (QAICc values). Notation: (.) constant; (t) time-dependence; (g) group effect; $(p=c)$ no recapture effect; $\left(\gamma^{\prime \prime}=\gamma^{\prime}=0\right)$ no emigration models; $\left(\gamma^{\prime \prime}=\gamma^{\prime}\right)$ random emigration models; $\left(\gamma^{\prime \prime} \gamma^{\prime}\right)$ Markovian emigration models.

\begin{tabular}{|c|c|c|c|c|c|c|}
\hline Model & QAICc & $\mathrm{Q} \triangle \mathrm{AICc}$ & AICc Weights & Likelihood & Parameters & QDeviance \\
\hline 1) $\phi(.) \gamma^{\prime}()=.\gamma^{\prime \prime}() p.(\mathrm{ts})=c(\mathrm{ts})$ & 271.67 & 0.00 & 0.882 & 1.000 & 36 & 268.35 \\
\hline 2) $\phi(\mathrm{g}) \gamma^{\prime}()=.\gamma^{\prime \prime}() p.(\mathrm{ts})=c(\mathrm{ts})$ & 277.33 & 5.65 & 0.052 & 0.059 & 39 & 266.75 \\
\hline 3) $\phi(.) \gamma^{\prime}(.) \gamma^{\prime \prime}() p.(\mathrm{ts})=c(\mathrm{ts})$ & 278.05 & 6.37 & 0.036 & 0.041 & 39 & 267.47 \\
\hline 4) $\phi(.) \gamma^{\prime}()=.\gamma^{\prime \prime}()=.0 p(\mathrm{ts})=c(\mathrm{ts})$ & 279.00 & 7.32 & 0.022 & 0.025 & 37 & 273.27 \\
\hline 5) $\phi(.) \gamma^{\prime}(\mathrm{g}) \gamma^{\prime \prime}(\mathrm{g}) p(\mathrm{ts})=c(\mathrm{ts})$ & 281.84 & 10.16 & 0.005 & 0.006 & 41 & 266.36 \\
\hline 6) $\phi(\mathrm{t}) \gamma^{\prime}()=.\gamma^{\prime \prime}() p.(\mathrm{ts})=c(\mathrm{ts})$ & 285.15 & 13.47 & 0.001 & 0.001 & 42 & 267.19 \\
\hline 7) $\phi\left(\mathrm{g}^{*} \mathrm{t}\right) \gamma^{\prime}()=.\gamma^{\prime \prime}() p.(\mathrm{ts})=c(\mathrm{ts})$ & 294.27 & 22.60 & 0.000 & 0.000 & 47 & 263.76 \\
\hline 8) $\phi(.) \gamma^{\prime}()=.\gamma^{\prime \prime}() p.(\mathrm{ts}) c(\mathrm{ts})$ & 304.42 & 32.75 & 0.000 & 0.000 & 56 & 250.44 \\
\hline 9) $\phi(.) \gamma^{\prime}()=.\gamma^{\prime \prime}() p.\left(\mathrm{~g}^{*} \mathrm{ts}\right)=c(\mathrm{~g} * \mathrm{ts})$ & 321.43 & 49.75 & 0.000 & 0.000 & 62 & 251.13 \\
\hline 10) $\phi(.) \gamma^{\prime}()=.\gamma^{\prime \prime}() p.(\mathrm{~g} * \mathrm{ts}) c(\mathrm{~g} * \mathrm{ts})$ & 409.69 & 138.01 & 0.000 & 0.000 & 98 & 228.70 \\
\hline
\end{tabular}

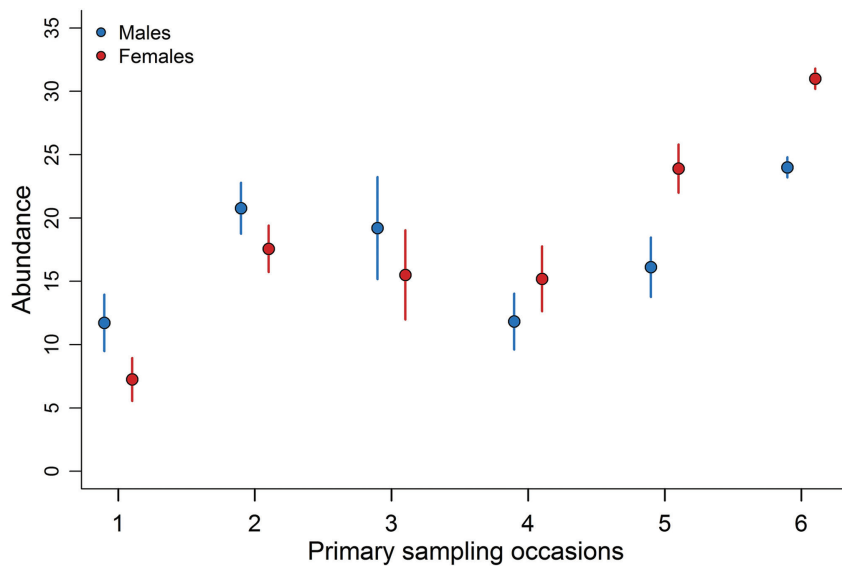

Fig. 3. Abundance estimates for males (Blue) and females (Red) of longsnout seahorses, Hippocampus reidi, for all primary sampling occasions. Whiskers represent Standard Errors.

\section{Discussion}

Our results provide a snapshot of a longer-term local population dynamics of $H$. reidi and represent a valuable reference line to improve our understanding of the ecology of this seahorse species. Taken together, the high survival probability between secondary periods and the low emigration probabilities suggest site fidelity, highlighting the importance of the area for seahorses. By estimating parameters of a longsnout seahorse population for the first time, our study shows how mark-recapture experiments using Pollock's Robust Design can help to characterize local population dynamics of seahorses, which we hope will inspire similar studies with other populations throughout the species distribution.

Our studied population shows similar sex ratio, the proportion of juveniles, and body size when compared to other seahorse populations (Foster, Vincent, 2004). The 1:1 sex ratio suggests a monogamic mating system, as seen among most seahorse species (Foster, Vincent, 2004). Monogamy might be feasible to increase reproductive success, given that seahorses usually live in low densities, have restricted mobility, and are cryptic to avoid predation (Vincent, Sadler, 1995; Foster, Vincent, 2004). The few populations with unequal sex ratio among seahorses (Bell et al., 2003; Martin-Smith, Vincent, 2005) may reflect overexploitation of individuals for commercial purposes (Rosa et al., 2007). The average body size of our studied individuals lay within the range recorded for other populations along the Brazilian coast (6.1 to $14.2 \mathrm{~cm}$; Rosa et al., 2007). The slightly larger body size of females - also known for other seahorse species (Foster, Vincent, 2004) - may be positively correlated with offspring production (Vincent, Giles, 2003).

The presence of pregnant individuals and couples in mating activities during our study agrees with suggestions that longsnout seahorses reproduce throughout the year (Rosa et al., 2007; Mai, Velasco 2011; Silveira et al., 2016). Moreover, reproductive activities suggest that the area provides conditions for the maintenance of the population. Despite being close to the subtropical limit of distribution of the species, this population does not seem to display seasonal reproductive activities. The low proportion of juveniles in this coastal population is somewhat expected (Moreau, Vincent, 2004; Martin-Smith, Vincent, 2005) since most of the juvenile phase of the species occurs in the pelagic environment (Curtis, Vincent, 2006).

By exhibiting a patchy distribution pattern, the Hippocampus genus tends to present low population densities (Lourie et al., 2004; Foster, Vincent, 2004). In overfished locations, $H$. reidi present lower average densities, from as low as 0.18 individuals $/ 100 \mathrm{~m}^{2}$ in the subtropical south to 6.6 individuals $/ 100 \mathrm{~m}^{2}$ in the tropical northeast of the Brazilian coast (Rosa et al., 2007). Our findings agree with such low density of subtropical populations near the southern limit of distribution of this species, although this is still a controversial ecological pattern given the lack of clearer empirical support (Sexton et al., 2009).

Seahorses are mostly sedentary; they are incapable of active long-distance migration and show no large-scale 
movements (Caldwell, Vincent, 2012; Boehm et al., 2013). These features were evident in our models suggesting constant and random patterns of temporary emigration. Overall, our findings suggest that longsnout seahorses have strong site fidelity, with low emigration probability and high survival rates through time. The lifespan of this species in the wild was estimated to be around three years (Mai, Velasco, 2011); thus, our sampling effort was probably concentrated in a single cohort. The capture and recapture probabilities were variable both between and among primary occasions and might have been influenced by environmental conditions, such as water turbidity. As the water visibility was very variable in the sampling area, it may have affected capture probabilities through active visual searching. Nevertheless, abundance estimates were relatively constant after the first month of the mark-recapture experiment, which reinforces the robustness of our model estimates to parameter co-variation.

Although we focused on quantifying population parameters in a population, its local dynamics is coupled with a broader-scale dynamic, being influenced by other mechanisms such as dispersal, climate variability and biological interactions (Bjørnstad et al., 1999). For instance, despite having small home ranges, being poor swimmers and being highly associated with the substrate, seahorses can perform long-distance dispersal by passively rafting in floating algal mats (Boehm et al., 2013). This passive dispersal might exert a strong influence in the meta-population dynamics of seahorse species. Therefore, we suggest that future efforts for quantifying seahorse population trends should incorporate the possible influence of all these other variables to clarify their roles in the demographical dynamics.

Considering the lack of knowledge about seahorse populations in natural environments and the ongoing threats they are exposed to, our study provides baseline knowledge that aids the comprehension of the population ecology of longsnout seahorse Hippocampus reidi. Importantly, our study demonstrates how mark-recapture methods, such as Pollock's Robust Design, are suitable for studies with Syngnathids, and we recommend longer studies using this framework throughout the distribution of the species. Such future large-scale effort will improve our understanding of the ecology of natural populations of seahorses and, more specifically, provide the information that hitherto prevents the assessment of the conservation status of $H$. reidi.

\section{Acknowledgments}

We thank all researchers who helped with field work, in particular Sergio R. Floeter for making his lab logistics available. We also thank the Instituto Chico Mendes de Conservação da Biodiversidade (ICMBio) for licensing the study (authorization number 40311-2). This study was carried out in association with the Projeto Hippocampus, a non-for-profit organization supported by Petrobras Ambiental.

\section{References}

Bell EM, Lockyear JF, McPherson JM. First field studies of an endangered South African seahorse, Hippocampus capensis. Environ Biol Fishes. 2003; 67:35-46.

Bjorndal KA, Bolten AB, Chaloupka MY. Survival probability estimates for immature green turtles Chelonia mydas in the Bahamas. Mar Ecol Prog Ser. 2003; 252:273-81.

Bjørnstad ON, Ims RA, Lambin X. Spatial population dynamics: analyzing patterns and processes of population synchrony. Trends Ecol Evol. 1999; 14:427-32.

Boehm JT, Woodall L, Teske PR, Lourie SA, Baldwin C, Waldman J, Hickerson M. Marine dispersal and barriers drive Atlantic seahorse diversification. J Biogeogr. 2013; 40:1839-49.

Burnham KP, Anderson DR. Data-based selection of an appropriate biological model: the key to modern data analysis. In: McCullough DR, Barrett RH, editors. Wildlife 2001: populations. London: Elsevier Applied Science; 1992. p.16-30.

Caldwell IR, Correia M, Palma J, Vincent ACJ. Advances in tagging syngnathids, with the effects of dummy tags on behaviour of Hippocampus guttulatus. J Fish Biol. 2011; 78:1769-85.

Caldwell IR, Vincent ACJ. A sedentary fish on the move: effects of displacement on long-snouted seahorse (Hippocampus guttulatus Cuvier) movement and habitat use. Environ Biol Fishes. 2013; 96(1):67-75.

Cantor M, Wedekin LL, Daura-Jorge FG, Rossi-Santos MR, Simões Lopes PC. Assessing population parameters and trends of Guiana dolphins (Sotalia guianensis): an eight-year markrecapture study. Mar Mam Sci. 2012; 28(1):63-83.

Convention on International Trade in Endangered Species of wild Fauna and Flora (CITES). Appendix II of the Convention on International Trade in Endangered Species of wild Fauna and Flora. 2016. Available from: http://www.cites.org/eng/app/ appendices.php

Connolly RM, Melville AJ, Preston KM. Patterns of movement and habitat use by leafy seadragons tracked ultrasonically. J Fish Biol. 2002; 61:684-95.

Correia M, Palma J, Koldewey H, Andrade JP. The use of a noninvasive tool for capture-recapture studies on a seahorse Hippocampus guttulatus population. J Fish Biol. 2014; 84:872-84.

Coston-Clements L, Settle LR, Hoss DE, Cross FA. Utilization of the Sargassum habitat by marine invertebrates and vertebrates a review. NOAA Technical Memorandum NMFS-SEFSC-296; 1991. Available from: https://permanent.access.gpo.gov/ gpo8250/TM_296_Coston-Clements_etal.pdf

Curtis JMR, Vincent ACJ. Life history of an unusual marine fish: survival, growth and movement patterns of Hippocampus guttulatus (Cuvier 1829). J Fish Biol. 2006; 68:707-33.

Dulvy NK, Ellis JR, Goodwin NB, Grant A, Reynolds JD, Jennings $\mathrm{S}$. Methods of assessing extinction in marine fishes. Fish Fish. 2004; 5:255-76.

Foster S, Vincent ACJ. The life history and ecology of seahorses: implications for conservation and management. J Fish Biol. 2004; 65:1-61. 
Freitas MO, Velastin R. Ichthyofauna associated with a culture of mussel Perna perna in Northern Santa Catarina, Southern Brazil. Acta Sci Biol Sci. 2010; 32:31-37.

Frick WF, Reynolds DS, Kunz TH. Influence of climate and reproductive timing on demography of little brown myotis Myotis lucifugus. 2010; 79:128-36.

Gotelli NJ, Colwell RK. Quantifying biodiversity: procedures and pitfalls in the measurement and comparison of species richness. Ecol Lett. 2001; 4:379-91.

Hamilton H, Saarman N, Short G, Sellas AB, Moore B, Hoang T, Grace CL, Gomon M, Crow K, Simison WB. Molecular phylogeny and patterns of diversification in syngnathid fishes. Mol Phylogenet Evol. 2017; 107:388-403.

Hanski I. Metapopulation dynamics. Nature. 1998; 396:41-49.

Hammond EL, Antony RG. Mark-recapture estimates of population parameters for selected species of small mammals. J Mammal. 2006; 87(3):618-27.

Huggins RM. On the statistical analysis of capture-recapture experiments. Biometrika. 1989; 76:133-40.

IUCN. IUCN Red List of Threatened Species. Version 2016-1. 2016. Available from: www.iucnredlist.org

Kendall WL, Nichols JD. On the use of secondary capturerecapture samples to estimate temporary emigration and breeding proportions. J Appl Stat. 1995; 22:751-62.

Kendall WL, Nichols JD, Hines JE. Estimating temporary emigration using capture-recapture data with Pollock's robust design. Ecology. 1997; 78(2):563-78.

Lebreton JD, Burnham KP, Clobert J, Anderson DR. Modeling survival and testing biological hypotheses using marked animals: A unified approach with case studies. Ecol Monogr. 1992; 62:67-118.

Lourie SA, Foster SJ, Cooper EWT, Vincent ACJ. A Guide to the Identification of Seahorses. Project Seahorse and TRAFFIC North America. Washington: University of British Columbia and World Wildlife Fund; 2004.

MaiACG, Rosa IML. Ecological aspects of the seahorse Hippocampus reidi in the Camurupim/Cardoso estuary, Piauí State, Brazil, as subsidies for the implementation of an Environmental Protection Area. Biota Neotrop. 2009; 9(3):85-91.

Mai ACG, Velasco G. Population dynamics and reproduction of wild longsnout seahorse Hippocampus reidi. J Mar Biol Assoc U K. 2011; 92(2):421-27.

Martin-Smith KM, Vincent ACJ. Seahorse declines in the Derwent estuary, Tasmania in the absence of fishing pressure. Biol Conserv. 2005; 123:533-45.

Moreau MA, Vincent ACJ. Social structure and space use in a wild population of the Australian short-headed seahorse Hippocampus breviceps Peters, 1869. Mar Freshwater Res. 2004; 55:231-39.

Otis DL, Burnham KP, White CG, Anderson DR. Statistical inference from capture data on closed animal population. Wildlife Monogr. 1978; 62:3-135.

Pollock KH. A capture-recapture design robust to unequal probability of capture. J Wildl Manag. 1982; 46:757-60.

R Development Core Team. R: a language and environment for statistical computing. Vienna: R Foundation For Statistical Computing; 2016. Available from: https://cran.r-project.org/
Rosa IL, Oliveira TPR, Castro ALC, Moraes LES, Xavier JHA, Nottingham MC, Dias TLP, Bruto-Costa LV, Araújo ME, Birolo AB, Mai ACG, Monteiro-Neto C. Population characteristics, space use and habitat associations of the seahorse Hippocampus reidi (Teleostei: Syngnathidae). Neotrop Ichthyol. 2007; 5(3):405-14.

Rotheray EL, Bussière LF, Moore P, Bergstrom L, Goulson D. Mark recapture estimates of dispersal ability and observations on the territorial behaviour of the rare hoverfly, Hammerschmidtia ferruginea (Diptera, Syrphidae). J Insect Conserv. 2014; 18:179-88.

Sanchez-Camara J, Booth DJ, Murdoch J, Watts D, Turon X. Density, habitat use and behavior of the weedy seadragon Phyllopteryx taeniolatus (Teleostei: Syngnathidae) around Sydney, New South Wales, Australia. Mar Freshwater Res. 2006; 57:737-45.

Seber GAF. The estimation of animal abundance and related parameters. New York: Macmillan Publishing; 1982.

Sexton JP, McIntyre PJ, Angert AL, Rice KJ. Evolution and ecology of species range limits. Annu Rev Ecol Evol Syst. 2009; 40:415-36.

Silveira RB. Dinâmica populacional do cavalo-marinho Hippocampus reidi (Syngnathidae) no manguezal de Maracaípe, Ipojuca, PE. [PhD Thesis]. Porto Alegre, RS: Pontifícia Universidade Católica do Rio Grande do Sul; 2005.

Silveira RB. Record of seahorses (Syngnathidae: Hippocampus) along the Brazilian coast. Oecologia Australis. 2011; 15(2):232-41.

Silveira RB, Silva JRS, Ferreira NF. Reproductive period, average height for the development of the brood pouch and sexual maturation of the seahorse Hippocampus reidi (Syngnathidae) in the northeast of Brazil. AARJMD. 2016; 3(3):140-52.

Teske PR, Hamilton H, Matthee CA, Barker NP. Signatures of seaway closures and founder dispersal in the phylogeny of a circumglobally distributed seahorse lineage. BMC Evol Biol. 2007; 7:138.

Vincent ACJ, Giles BG. Correlates of reproductive success in a wild population of Hippocampus whitei. J Fish Biol. 2003; 63:344-55.

Vincent ACJ, Sadler LM. Faithful pair bonds in wild seahorses, Hippocampus whitei. Anim Behav. 1995; 50:1557-69.

Wayne AF, Maxwell MA, Ward CG, Vellios CV, Matthew R. Williams MR, Pollock KH. The responses of a critically endangered mycophagous marsupial (Bettongia penicillata) to timber harvesting in a native eucalypt forest. Forest Ecol Manag. 2016; 363:190-99.

White GC, Burnham KP. Program MARK: Survival estimation from populations of marked animals. Bird Stud. 1999; 46:120-39.

Williams BK, Nichols JD, Conroy MJ. Analysis and management of animal populations. Cambridge: Academic Press; 2002.

Submitted 26 May, 2017 Accepted 26 November, 2017 by Franco Texeira de Mello 
